\title{
Mapping the Road From Childhood Trauma to Adult Somatization: the Role of Attachment
}

\section{Citation}

Waldinger, Robert J., Marc S. Schulz, Arthur J. Barsky, and David K. Ahern. 2006. "Mapping the Road From Childhood Trauma to Adult Somatization: The Role of Attachment." Psychosomatic Medicine 68 (1): 129-35. https://doi.org/10.1097/01.psy.0000195834.37094.a4.

\section{Permanent link}

http://nrs.harvard.edu/urn-3:HUL.InstRepos:38846192

\section{Terms of Use}

This article was downloaded from Harvard University's DASH repository, and is made available under the terms and conditions applicable to Other Posted Material, as set forth at http:// nrs.harvard.edu/urn-3:HUL.InstRepos:dash.current.terms-of-use\#LAA

\section{Share Your Story}

The Harvard community has made this article openly available.

Please share how this access benefits you. Submit a story.

Accessibility 
Waldinger, R.J., Schulz, M.S., Barsky, A.J., \& Ahern, D.K. (2006). Mapping the road from childhood trauma to adult somatization: The role of attachment. Psychosomatic Medicine, 68, 129-135.

Mapping the Road from Childhood Trauma to Adult Somatization:

The Role of Attachment

Robert J. Waldinger, M.D.

Brigham and Women's Hospital and Harvard Medical School

Marc S. Schulz, Ph.D.

Bryn Mawr College

Arthur J. Barsky, M.D.

Brigham and Women's Hospital and Harvard Medical School

David K. Ahern, Ph.D.

Brigham and Women's Hospital and Harvard Medical School 
Mapping the Road from Childhood Trauma to Adult Somatization:

The Role of Attachment

Robert J. Waldinger

Marc S. Schulz

Arthur J. Barsky

David K. Ahern 


\begin{abstract}
Objective: This study tested whether insecure attachment mediates the link between childhood trauma and adult somatization. Methods: A community sample of 101 couples completed self-report measures including the Relationship Scales Questionnaire, the Childhood Trauma Questionnaire, the Somatic Symptom Inventory, the Beck Depression Inventory, and the Conflict Tactics Scale. Results: Childhood trauma was associated with higher levels of somatization and insecure attachment. Insecure attachment style was also associated with higher levels of somatization. Controlling for age, income, and recent intimate partner violence, analyses showed that fearful attachment fully mediated the link between childhood trauma and somatization for women. For men there was no such mediation, but both childhood trauma and insecure attachment styles made independent contributions to predicting levels of somatization. Conclusions: Findings are consistent with the hypothesis that, for women, childhood trauma influences adult levels of somatization by fostering insecure adult attachment. For men, findings suggest that trauma and attachment are both important independent predictors of adult somatization. Study results support the idea that childhood trauma shapes patients' styles of relating to others in times of need and these styles in turn influence the somatization process and how patients respond to providers. Screening for attachment style may provide information that could allow health care providers to tailor treatment more effectively. Key words: Attachment style, somatization, childhood trauma, interpersonal models. Abbreviations: CTQ = Childhood Trauma Questionnaire; CTS2 = Conflict Tactics Scale version 2; SSI = Somatic Symptom Inventory; RSQ = Relationship Scales Questionnaire; BDI = Beck Depression Inventory.
\end{abstract}




\section{INTRODUCTION}

It is estimated that between $30 \%$ and $60 \%$ of patients in primary care settings complain of symptoms that have no medical basis (1). The development and persistence of these unexplained symptoms is commonly termed somatization, and symptoms tend to be interpreted by those who suffer from them as indicating serious medical problems. Understanding the factors that foster and maintain somatization is crucial to improving prevention as well as treatment of those who present to health care facilities with medically unexplained symptoms. Numerous studies suggest that early adverse life experiences contribute to the development of somatization in adulthood (2). In particular, histories of interpersonal childhood trauma (sexual abuse, physical abuse, emotional abuse, and neglect) have been linked with somatization in adults (3-5).

Although a correlational association between childhood trauma and somatization in adulthood has been established, the mechanism by which early traumatic events might give rise to these later symptoms is not well understood. Many people with histories of childhood trauma do not manifest medically unexplained symptoms as adults. Why might some people with such histories experience somatization while others do not? Stuart and Noyes (2) theorized that internalized schemas related to attachment to important people, particularly parental figures, are a key link in the pathway from childhood trauma to adult somatic preoccupations. They hypothesize that adverse relationship experiences in childhood foster the development of insecure models of attachment, and that insecure attachment in turn may make adults more vulnerable to somatization. The study reported here tested this model - specifically, that the effects of childhood trauma on adult somatization are mediated by insecure attachment.

Childhood trauma and somatization. Interpersonal childhood traumas (including sexual abuse, physical abuse, emotional abuse, and neglect) have been linked empirically with adults' 
reports of a wide range of symptoms for which there is no medical explanation $(3,4)$, including chronic pain (6), headache (7), gynecological complaints (8), gastrointestinal symptoms (9), and musculoskeletal symptoms (7). Although most studies have examined only sexual and physical abuse, more recent work has shown that emotional abuse and neglect are linked with somatization as well (5). Because they have been intruded upon bodily or had basic physical or emotional needs left unattended to by caregivers, survivors of child abuse and neglect are thought to be vulnerable to concerns about bodily functioning and integrity later in life.

Attachment and somatization. Theory suggests that this vulnerability might be linked to internal attachment schemas that individuals develop about themselves and others, but few empirical investigations have been conducted in this area. Bowlby (10) first proposed the idea that repeated interactions between infants and their caregivers prompt infants to develop models of both seeking and receiving care from those on whom they depend. These models, or attachment styles, tend to persist throughout life and influence the expectations that people bring to their dealings with others - particularly to their dealings with those they might depend on for needed support or advice such as family members, romantic partners and physicians (11).

Bartholomew and Horowitz (12) empirically validated a classification system of one secure and three insecure adult attachment styles. According to this system, people with a secure attachment style generally recall consistently reliable caregiving as children, have a positive view of self and others, and are comfortable depending on others. People with a dismissing attachment style typically report experiencing unresponsive caregiving, resulting in the need to see themselves as self-sufficient because others cannot be relied upon. Adults with a preoccupied attachment style tend to report having had caregivers who were not consistently responsive to their needs. This inconsistency fosters the development of a negative image of the 
self as unlovable, along with the expectation that others are able but not always willing to provide support. Never sure of getting what they need, preoccupied individuals become vigilant and "clingy" in efforts to get support from others. By contrast, those with a fearful attachment style typically report rejecting experiences with caregivers, resulting in negative images of both self and others. Fearfully attached adults long for closeness but fear rejection and as a result vacillate between approach and avoidance behaviors when attempting to get close to others.

Consistent with theory, several prior studies have found associations between insecure attachment styles and increased somatic symptom reporting. Taylor et al (13) surveyed more than 2000 patients in primary care offices and found that those who endorsed insecure attachment styles were significantly more likely than securely attached adults to present with medically unexplained physical symptoms. In a large $(\mathrm{N}=701)$ sample of female primary care patients in a health maintenance organization, Ciechanowski and colleagues (14) found that patients with insecure attachment styles reported a significantly greater number of physical symptoms than those with a secure attachment style, and the strongest association was between fearful attachment style and greater symptom reporting. Similarly, Noyes and colleagues (11) found that insecure attachment, especially fearful attachment, was associated with greater symptom reporting in a sample of 162 patients in a general medical clinic. A critical question is whether attachment style might help explain the associations found previously between childhood trauma and adult somatic symptoms.

Childhood trauma and attachment. There is empirical support for an association between childhood trauma and insecure attachment styles in adulthood. For example, Stalker and Davies (15) found a high percentage of childhood sexual abuse survivors to be preoccupied and insecurely attached. In large community samples, both Alexander (16) and Styron (17) found 
links between sexual abuse histories and insecure adult attachment styles. The empirical associations established in prior studies between childhood trauma and somatization, between childhood trauma and attachment, and between attachment and somatization are consistent with the hypothesis that insecure attachment mediates the relation between childhood trauma and increased somatic symptom reporting in adults. According to this hypothesis, childhood trauma fosters the development of insecure attachment, including the expectation that others will not meet one's emotional needs. This expectation, in turn, promotes increased emphasis on and reporting of somatic concerns as a way to seek help from those who are expected to be unresponsive to emotional distress.

The present study represents the first test of this full model in which adverse childhood experiences foster adult somatization through their effect on attachment. In contrast to the majority of prior studies that have recruited participants from mental health and/or medical clinic populations, we test this model using a community-based sample. Clinical samples are likely to have higher levels of medical illness and emotional distress. A community sample offers the advantage of examining links between childhood trauma and somatization in people who have not come specifically seeking care. In addition, we measured and controlled for several factors that have been linked to both medical illness and somatization: age, socioeconomic status, and recent experiences of physical violence from an intimate partner (18). Finally, we examined current levels of depression, both because depression is commonly associated with somatization (11) and because depressive symptoms may bias participants toward more negative responses to other assessments (including physical symptom inventories).

\section{METHOD}

Subjects 
One hundred nine couples participated in a study of communication. Participants were recruited through advertisements in the Boston metropolitan area. A community-based sample was recruited with oversampling of women who had histories of childhood abuse and couples with recent histories of man-to-woman physical violence. Eligible couples had to be living together for a minimum of 12 months (but not necessarily married) prior to participating in the study, and fluent in English. Couples were recruited into four groups - those in which the woman had a history of abuse occurring between the ages of 7 and 18 (sexual abuse perpetrated by someone living in the home, with our without physical abuse, emotional abuse, or neglect) $(\mathrm{N}=31)$, those in which the man reported recent physical violence toward his partner $(\mathrm{N}=28)$, couples in which both conditions were reported $(\mathrm{N}=23)$, and couples who reported neither condition ( $\mathrm{N}=27)$. To qualify as abused, the woman had to report a history of sexual abuse on the Childhood Trauma Questionnaire $(\mathrm{CTQ}, 19)$ perpetrated by someone at least 5 years older living in the home. Men were categorized as violent if women reported on the Conflict Tactics Scales (CTS2, 20) that their partners were physically violent at least twice in the prior year. Women were screened by telephone interview to ascertain eligibility of the couple for one of the four recruitment groups described above. IRB-approved written informed consent was obtained. Couples came to our laboratory for two sessions, during which they completed questionnaires and participated in a videotaped marital discussion and individual interviews. They were paid $\$ 250$ (\$125 per person) for their participation. Eight couples did not complete both laboratory sessions, resulting in complete data for 101 couples. Instruments

Somatization. Current somatization was assessed using the Somatic Symptom Inventory (SSI). (Note that this is distinct from the Somatic Symptom Index, also abbreviated SSI, 
developed by Escobar and colleagues (21).) The SSI is a self-report questionnaire comprised of 26 bodily complaints drawn from the hypochondriasis scale of the Minnesota Multiphasic Personality Inventory and the Hopkins Symptom Checklist somatization scale (22). The testretest reliability and convergent and external validity of the SSI have been established $(23,24)$. In this study, Cronbach's alpha indexing internal consistency was 0.89. SSI scores are associated with the number of medically unexplained symptoms in the patient's medical record, physician ratings of patient somatization, and the diagnosis of somatization disorder (25-27).

Childhood trauma. Histories of childhood trauma were assessed using the 28-item Short Form of the Childhood Trauma Questionnaire (CTQ) (19). Items on the CTQ ask about experiences of sexual abuse, physical abuse, emotional abuse, physical neglect, and emotional neglect in childhood and adolescence and are rated on a 5-point, Likert-type scale with response options ranging from Never True $($ score $=1)$ to Very Often True (score $=5$ ). The CTQ has been shown to yield reliable and valid retrospective assessments of childhood abuse and neglect (19). A total childhood trauma score (summing all 5 subscale scores) was used in the present study to incorporate the full range of experiences into one variable and to improve the overall reliability of the measure. Scores ranged from 25 to 125 . Cronbach's alpha for this overall scale was 0.82 .

Attachment style. Attachment style was measured using the Relationship Scales Questionnaire (RSQ) (28). The RSQ is a 30-item questionnaire based on the four-category model of adult attachment described above. Participants rate each item on a 5-point Likert-type scale reflecting the degree to which each item is characteristic of them. The RSQ has demonstrated good reliability and convergent validity (12). Continuous scores on the four attachment subscales - secure, dismissing, fearful, and preoccupied - were derived by computing the mean rating for items on each scale. 
Intimate partner violence. The presence or absence of intimate partner violence was assessed using the Conflict Tactics Scale - Version 2 (CTS-2) (20). The CTS-2 is a 78-item selfreport questionnaire asking about the frequency and severity of participants' behaviors during conflicts in the past year. Participants were categorized as violent if at a minimum they endorsed acts such as slapping or shoving the partner, or twisting the partner's arm or hair. The CTS-2 has demonstrated good reliability and good discriminant and construct validity (20).

Depressive symptoms. Depressive symptoms were measured using the Beck Depression Inventory (BDI) (30). The BDI is a 21-item self-report scale that assesses cognitive, affective, and somatic depressive symptoms that have occurred over the previous week. This scale measures depressive symptoms but is not a diagnostic tool to assess major depressive disorder. It has acceptable test-retest reliability in non-clinical populations, and demonstrates concurrent validity in clinical and non-clinical samples.

Analyses

Distributions and descriptive statistics were examined for all variables. For two predictor variables (man's CTQ and BDI scores) and the outcome variable (men's and women's SSI scores), outlying data points were reduced to 3 standard deviations above the mean to reduce their influence on analyses. All analyses were conducted separately for men and for women. Relations between CTQ abuse scores and SSI scores, and between RSQ attachment scales and SSI scores were examined by calculating matrices of Pearson correlation coefficients. Pearson correlation coefficients were used to examine links between somatization and three variables that might confound links between abuse or attachment and somatic symptoms: age, household income, and current level of depressive symptoms. T-tests were used to examine links between SSI scores and two additional potential confounding variables - marital status and the presence 
or absence of recent physical victimization by partner. According to both Baron and Kenny (31) and Kraemer et al (32), in order for attachment to be a mediator, it must be correlated with both the predictor (trauma) and the outcome (somatic symptoms). In addition, the predictor (trauma) must be linked with the outcome (somatic symptoms). If these criteria are met, then hierarchical linear regression analyses are used to test whether attachment scales mediate - that is, reduce the regression coefficient indexing - the link between childhood trauma and somatization. Age, household income, and recent experience of physical violence from partner were controlled for in Step 1. Total CTQ trauma score was introduced in Step 2, and attachment scale scores in Step 3. As a final stringent test of the model, BDI scores were introduced in Step 4 to assess whether the linkages found remained after accounting for depressive symptoms.

\section{RESULTS}

Complete data were available for 101 men and 101 women. Demographic characteristics of the sample are presented in Table 1 . Sexual abuse was reported by $56 \%$ of women in this sample and $17 \%$ of men, physical abuse by $26 \%$ of women and $38 \%$ of men, and emotional abuse by $51 \%$ of women and $36 \%$ of men. Compared with men, women reported significantly more trauma; the mean trauma score (5 subscales combined) for men was $44.3(\mathrm{SD}=15.6)$, and for women $58.8(\mathrm{SD}=24.0)$. Forty-eight percent of women reported male violence toward them in the previous 12 months, and $48 \%$ of women reported that they had been physically violent toward their partners in the previous 12 months. The mean level of depressive symptoms on the BDI was $10.1(\mathrm{SD}=10.0)$ for women and $8.1(\mathrm{SD}=6.9)$ for men, with $13 \%$ of women and $4 \%$ of men reporting moderate to severe levels of depression (scores greater than 19).

Correlations among variables in the mediational model. As shown in Table 2, for both women and men, somatization (SSI) scores were significantly correlated in the expected 
direction with the amount of childhood trauma reported. SSI scores were also significantly linked in the expected directions with fearful, preoccupied, and secure attachment for women, and with fearful, dismissing, and secure attachment for men. To justify further investigation of mediational models, attachment scores that are significantly linked with somatization must also be significantly linked with childhood trauma. For women, Pearson correlations revealed significant relations between childhood trauma and all three of the attachment scales that were linked with somatization: fearful attachment, $r=.52, p<.001$, preoccupied attachment, $r=.25, p$ $=.01$, and secure attachment, $r=-.39, p<.001$. For men, Pearson correlations revealed significant relations between childhood trauma and one of the three attachment scales linked to somatization: fearful attachment, $r=.24, p=.01$.

Potential influence of age, income, and depressive symptoms. Links between potential confounding variables and somatization were also examined. As shown in Table 2, age was significantly correlated with SSI scores for men but not for women, whereas recent physical victimization by partner and annual household income were significantly linked with SSI scores for women but not for men. Current level of depressive symptomatology was significantly correlated with SSI scores for both women and men. T-tests revealed that women who were the target of intimate partner violence reported more somatic symptoms than women whose partners were not violent toward them, $t(99)=-3.5, p=.001$. For men, somatization was not linked to partners' violence, $t=-.65, \mathrm{df}=99, p=.52$. No significant links were found between marital status and SSI scores (women: $t=.65, \mathrm{df}=99, p=.52$; men, $t=.25$, df $=99, p=.80$ ), so marital status was not included in the regression models reported below.

Testing the mediational model. Table 3 presents the results of two hierarchical regression models testing whether attachment style mediates links between childhood trauma and 
somatization. Age, household income and history of recent intimate partner violence were included in Step 1 as covariates and accounted for between 9 and $18 \%$ of the variance in somatization, respectively, for men and women. Childhood trauma was introduced in Step 2 and was a significant predictor of SSI scores even after controlling for the covariates in Step 1. For women, childhood trauma predicted an additional 5\% of the variance, and for men it predicted an additional $12 \%$ of the variance. Attachment scores were introduced in Step 3. For women, the attachment style variables explained an additional $7 \%$ of the variance and reduced the regression coefficient for trauma history to non-significance, supporting the hypothesis that attachment mediates the link between childhood trauma and somatization. Fearful attachment had the strongest link after controlling for all other variables in the model. For men, the addition of attachment scores in Step 3 explained an additional 11\% of the variance above and beyond childhood trauma and the covariates, but it did not substantially reduce the regression coefficient for trauma history. These findings suggest that for men, childhood trauma and attachment each make independent contributions to predicting SSI scores. The block of four attachment variables explained a significant amount of variance in somatization for men, but none of the four had a significant independent link with somatization after accounting for the influence of all the variables in the model. Depressive symptoms explained another $9 \%$ of the variance in somatization for women, but the minimal changes in the regression coefficients for the attachment variables from Step 3 to 4 indicate that most of this influence was independent of the mediating role of attachment. The standardized regression coefficient for fearful attachment was reduced somewhat but remained a marginally significant predictor of somatization. For men, depressive symptomatology did not explain a significant amount of additional variance and did not alter the links between childhood trauma and somatization. The results for men and women 
suggest that the influences of childhood trauma and attachment are largely independent of the influence that depressive symptoms might have on somatization. The final regression models explained $39 \%$ of the variance in women's SSI scores and $33 \%$ of the variance in men's SSI scores.

\section{DISCUSSION}

This study was designed to test a theoretical model that integrates findings from three lines of empirical work: studies linking childhood trauma with adult somatization, studies linking adult attachment style with somatization, and studies linking childhood trauma with insecure adult attachment style. To our knowledge, this is the first published study to test the mediating role of attachment in accounting for established associations between childhood trauma and somatization in adulthood. Our initial analyses replicated the three sets of independent associations found in previous studies. Our analyses also replicated the associations found in prior studies between reports of somatic symptoms and age, socioeconomic status, experiencing intimate partner violence, and depression.

For women in this sample, analyses supported the hypothesis that insecure attachment mediates the link between childhood trauma and adult somatization. Support was strongest for the mediating role of fearful attachment. How might we understand this mediational influence? A child who is abused or neglected by a needed adult caregiver may be particularly prone to develop an image of the self as unworthy of support from others and an image of caregivers as unreliable and even dangerous - images that form the basis of fearful attachment style. The sense that one's emotional 'neediness' might drive others away may, in turn, prompt minimization of negative affect, a compensatory focus on bodily sensations, and care-seeking for unexplained medical complaints. Moreover, fears about caregiver reliability may promote doctor-shopping 
and fragmentation of health care. From the perspective of the caregiver, these individuals are likely to be experienced as fragile, needy and difficult to reassure. This combination of caregiver and patient experience may create a dyadic feedback pattern that results in mutual misunderstanding and frustration, poor doctor-patient relationships, and sub-optimal care.

For the men in our sample, insecure attachment did not mediate the link between childhood trauma and somatization. However, both childhood trauma and insecure attachment made independent contributions to the prediction of SSI scores. No single insecure attachment style stood out as the key influence, but collectively the 3 insecure styles accounted for a significant portion of the variance in somatization. Our findings thus support differential associations for men and women. However, it is important to note that we oversampled women with histories of childhood sexual abuse, and women were more than three times as likely as men to have reported sexual abuse. The gender differences we found in associations among childhood trauma, attachment, and somatization may be related to the types of abuse suffered in each group. Perhaps attachment is particularly important in shaping the effects of childhood sexual abuse on adult somatization. This question should be explored in further research.

Although the effect sizes for the main links in our mediational model were moderate in strength (33), our data do not suggest that all traumatized children develop insecure attachment or that all insecurely attached adults report higher levels of somatic symptoms. There is evidence from other studies that biological and psychological factors may protect some individuals from the negative sequelae of exposure to early life stressors. Genetically based temperamental factors and adult experiences have been found to influence the way that individuals respond to early life stressors $(34,35)$. Childhood trauma appears to be a risk factor for insecure attachment, and insecure attachment may predispose an individual to somatization, but further 
research is needed to understand the particular biological, psychological and social factors that may amplify or buffer those risks.

An ever-present problem in the study of somatization is how to distinguish between symptom reporting that is consistent with demonstrable medical illness and symptom reporting that is not. In this study we had no independent measures of physical health and so could not establish that SSI scores reflected symptoms that lacked a demonstrable medical basis. Even with measures of medical morbidity, establishing whether reported symptoms are out of proportion to physical findings is a difficult task. For this reason, we controlled in our main analyses for the possible influence of age, socioeconomic status, and being the victim of intimate partner violence - factors that are associated empirically with medical illness. It is noteworthy that even after accounting for these factors, childhood trauma and insecure attachment remained significant predictors of somatization.

Because of the overlap of depression with the variables of interest, inclusion of depressive symptoms in the final step of our regression models provided a particularly stringent test of our model. Childhood trauma has been linked with adult depression (17), and insecure attachment style may both contribute to and be exacerbated by depression (36). (In this sample, correlations between depression and attachment scales ranged in magnitude from .01 to .47. The correlations between depressive symptoms and childhood trauma were .38 for men and .35 for women.) Individuals who are depressed are likely to show a negative response bias across most measures, and this bias may inflate connections found between measures. Thus, it is noteworthy that introducing depressive symptoms into the regression models did not significantly alter the central findings of the study regarding the impact of childhood trauma and insecure attachment.

This study has several limitations. First, the cross-sectional design establishes 
associations but cannot determine causality. Although the path from childhood trauma to adult attachment style to somatization makes sense temporally, it is possible that, for some children, the roots of insecure attachment precede the experience of trauma and persist or flourish in adulthood. It is also possible that somatization leads to disappointing interpersonal experiences, which in turn foster insecure adult attachment. Despite our efforts to control for variables associated with medical illness, the SSI scores undoubtedly reflect some degree of actual medical morbidity as well as somatization. Thus, we cannot determine the degree to which higher SSI scores simply reflected a higher incidence of medical illness. Second, despite solid empirical evidence for the validity of the CTQ, retrospective reporting of childhood trauma raises concerns about the accuracy of participant recall. Because we oversampled couples in which the woman had a history of childhood sexual abuse and where there had been recent man-to-woman physical violence, we must be circumspect about the generalizability of our findings to the general population. We do not have health care utilization data on our community sample, and so we are unable to examine how attachment status and abuse histories may be related to care-seeking in this population. Finally, by studying couples, we selected individuals who at the very least were able to establish intimate relationships, which might result in findings that underestimate the impact of childhood trauma on attachment.

This study is, to our knowledge, the first to test a model of how childhood trauma may lead to adult somatization, and this direction of research may have important clinical implications. People who seek care for medically unexplained physical symptoms often respond negatively to health care providers and use health care resources in maladaptive ways that result in sub-optimal care. Research linking somatization with child abuse and insecure attachment may help inform the design of clinical interventions that address some of the particular concerns 
that these patients bring to doctors' consulting rooms. For example, screening primary care patients for histories of childhood trauma can help clinicians be sensitive to many abuse survivors' fears about physical examinations, medical procedures, and boundaries in the doctorpatient relationship. Such fears threaten the therapeutic alliance and, if not addressed, can silently and repeatedly disrupt continuity of care.

Screening for attachment style, which is a simple procedure, may help health care providers design more patient-centered approaches to treatment, tailoring the provision of services to insecurely attached patients' particular concerns. For example, people with a dismissing attachment style bring the expectation that they will receive inadequate attention or care from others. These people may be especially worried about not being believed or taken seriously by health care providers. By contrast, a person with a preoccupied attachment style may be more concerned about losing the relationship with a health care provider once diagnostic testing is complete and no more treatment is indicated. Structured ongoing contact with a primary care provider even after treatment for particular problems is finished may reduce these worries. Fearfully attached individuals may avoid long-term care situations both because of concerns about greater intimacy with providers and because of their expectation that they will receive inadequate care. Greater outreach may be required to help these patients maintain ongoing relationships with providers rather than seeking care only in emergency settings.

More research is needed on ways to build therapeutic alliances with people who have insecure attachment and who have been victimized by past caregivers. By distinguishing among patients with different attachment styles and those with childhood trauma, we have the potential to create more differentiated modes of health care delivery that improve patients' ability to engage with health care providers as well as their rates of response to treatment. 


\section{References}

1. Kirmayer L, Robbins J: Three forms of somatization in primary care: prevalence, cooccurrence, and sociodemographic characteristics. Journal of Nervous and Mental Disease 179:647-655, 1991

2. Stuart S, Noyes RJ: Attachment and interpersonal communication in somatization. Psychosomatics 40:34-43, 1999

3. Barsky AJ, Wool C, Barnett MC, Cleary PD: Histories of childhood trauma in adult hypochondriacal patients. American Journal of Psychiatry 151:397-401, 1994

4. Sansone RA, Wiederman M, Sansone L: Adult somatic preoccupation and its relationship to childhood trauma. Violence \& Victims 16:39-47, 2001

5. Spertus I, Yehuda R, Wong C, Halligan S, Seremetis S: Childhood emotional abuse and neglect as predictors of psychological and physical symptoms in women presenting to a primary care practice. Child Abuse \& Neglect 27:1247-1258, 2003

6. Green CR, Flowe-Valencia H, Rosenblum L, Tait AR: The role of childhood and adulthood abuse among women presenting for chronic pain management. Clinical Journal of Pain 17:359-364, 2001

7. Bendixen M, Muus KM, Schei B: The impact of child sexual abuse: A study of a random sample of Norwegian students. Child Abuse \& Neglect 18:837-847, 1994

8. Cunningham J, Pearce T, Pearce P: Childhood sexual abuse and medical complaints in adult women. Journal of Interpersonal Violence 3:131-144, 1988

9. Bass C, Bond A, Gill D, Sharpe M: Frequent attenders without organic disease in a gastroenterology clinic: Patient characteristics and health care use. General Hospital Psychiatry 21:30-38, 1999 
10. Bowlby J: Attachment and loss, Vol. 1: Attachment. London, Hogarth, 1969

11. Noyes RJ, Stuart SP, Langbehn DR, Happel RL, Longley SL, Muller BA, Yagla SJ: Test of an interpersonal model of hypochondriasis. Psychosomatic Medicine 65:292-300, 2003

12. Bartholomew K, Horowitz L: Attachment styles among young adults: A test of a fourcategory model. Journal of Personality and Social Psychology 61:226-244, 1991

13. Taylor RE, Mann AH, White NJ, Goldberg DP: Attachment style in patients with unexplained physical complaints. Psychological Medicine 30:931-941, 2000

14. Ciechanowski PS, Walker EA, Katon WJ, Russo JE: Attachment theory: A model for health care utilization and somatization. Psychosomatic Medicine 64:660-667, 2002

15. Stalker CA, Davies F: Attachment organization and adaptation in sexually-abused women. Canadian Journal of Psychiatry 40:234-240, 1995

16. Alexander PC: The differential effects of abuse characteristics and attachment in the prediction of long-term effects of sexual abuse. Journal of Interpersonal Violence 8:346362,1993

17. Styron T, Janoff-Bulman R: Childhood attachment and abuse: Long-term effects on adult attachment, depression and conflict resolution. Child Abuse \& Neglect 21:1015-1023, 1997

18. Lown EA, Vega WA: Intimate partner violence and health: Self-assessed health, chronic health, and somatic symptoms among Mexican American women. Psychosomatic Medicine 63:352-360, 2001.

19. Bernstein DP, Fink L, Handelsman L, Foote J, Lovejoy M, Wenzel K, Sapareto E, Ruggerio J: Initial reliability and validity of a new retrospective measure of child abuse 
and neglect. American Journal of Psychiatry Vol 151:1132-1136, 1994

20. Straus MA, Hamby SL, Boney-McCoy S, Sugarman DB: The revised Conflict Tactics Scales (CTS2): Development and preliminary psychometric data. Journal of Family Issues 17:283-316, 1996

21. Escobar JI, Rubio-Stipec M, Canino G, Karno M: Somatic Symptom Index (SSI): A new and abridged somatization construct: Prevalence and epidemiological correlates in two large community samples. Journal of Nervous \& Mental Disease 177:140-146, 1989

22. Lipman R, Covi L, Shapiro A: The Hopkins Symptom Checklist (HSCL): factors derived from the HSCL-90. Psychopharmacology Bulletin 13:43-45, 1977

23. Weinstein M, C., PhD, Berwick D, M., MD, Goldman PA, MPH, Murphy J, M., PhD, Barsky A, J., MD: A comparison of three psychiatric screening tests using receiver operating characteristic (ROC) analysis. Medical Care 27:593-607, 1989

24. Barsky AJ, Wyshak G, Klerman GL: Transient hypochondriasis., Archives of General Psychiatry, Vol. 47, American Medical Assn, 1990, 746-752

25. Barsky A, Wyshak G, Latham K, Klerman G: Hypochondriacal patients, their physicians, and their medical care. Journal of General Internal Medicine 6:413-419, 1991

26. Barsky AJ, Wyshak G, Klerman GL: Medical and psychiatric determinants of outpatient medical utilization., Medical Care, Vol. 24, Lippincott Williams \& Wilkins, 1986, 548560

27. Barsky AJ, Cleary PD, Sarnie MK, Klerman GL: The course of transient hypochondriasis. American Journal of Psychiatry 150:484-488, 1993

28. Griffin D, Bartholomew K: Models of the self and other: Fundamental dimensions underlying measures of adult attachment. Journal of Personality and Social Psychology 
$67: 430-445,1994$

29. Margolin G: The multiple forms of aggressiveness between marital partners: How do we identify them? Journal of Marital and Family Therapy 13:77-84, 1987

30. Beck AT, Ward CH, Mendelson M, Mock JE, Erbaugh JK: An inventory for measuring depression. Archives of General Psychiatry 4:561-571, 1961

31. Baron RM, Kenny DA: The moderator-mediator variable distinction in social psychological research: Conceptual, strategic and statistical considerations. Journal of Personality \& Social Psychology 51:1173-1182, 1986

32. Kraemer HC, Stice E, Kazdin A, Offord D, Kupfer D: How do risk factors work together? Mediators, moderators, and independent, overlapping, and proxy risk factors. American Journal of Psychiatry 158:848-856, 2001

33. Cohen J: Statistical Power Analysis for the Behavioral Sciences. Hillsdale, N.J., Lawrence Erlbaum Associates, 1988

34. Whiffen V, Aube JA: Intimate relationships moderate the association between childhood sexual abuse and depression. Journal of Interpersonal Violence 14:940-954, 1999

35. Caspi A, McClay J, Moffitt T, Mill J, Martin J, Craig IW, Taylor A, Poulton R: Role of genotype in the cycle of violence in maltreated children. Science 297:851-854, 2002

36. Dozier M, Stovall KC, Albus KE: Attachment and psychopathology in adulthood. In Cassidy J, Shaver PR (eds), Handbook of attachment: Theory, research, and clinical applications., Guilford Press, 1999, 497-519 
Table 1

$\underline{\text { Sample characteristics. }}$

Mean age in years

$\operatorname{Men}(\underline{\mathrm{N}}=101)$

Women $(\underline{\mathrm{N}}=101)$

Percent married

Ethnic backgrounds

Caucasian

African-American

Hispanic

Other

Educational background

Bachelors or advanced degrees

High school graduate or some college

No high school diploma

Mean annual income

$$
\begin{aligned}
& 33.2(\mathrm{SD}=8.8) \\
& 31.6(\mathrm{SD}=8.6)
\end{aligned}
$$

$34 \%$

$59 \%$

$28 \%$

$8 \%$

$5 \%$

$45 \%$

$47 \%$

$8 \%$

$\$ 30,000-\$ 45,000$ 


\section{Table 2.}

Pearson correlations of childhood trauma, attachment, age, income, and current depression with $\underline{\text { somatization }}$

\begin{tabular}{|c|c|c|c|c|}
\hline & \multicolumn{4}{|c|}{ Somatization } \\
\hline & \multirow{2}{*}{\multicolumn{2}{|c|}{$\begin{array}{l}\text { Women } \\
\underline{\mathrm{N}}=101\end{array}$}} & \multicolumn{2}{|c|}{ Men } \\
\hline & & & & 101 \\
\hline & $r$ & $p$ & $r$ & $p$ \\
\hline Childhood trauma & .27 & .004 & .30 & .001 \\
\hline Fearful attachment & .40 & $<.001$ & .35 & $<.001$ \\
\hline Preoccupied attachment & .20 & .04 & -.10 & .34 \\
\hline Dismissing attachment & .05 & .61 & .23 & .02 \\
\hline Secure attachment & -.30 & .003 & -.26 & .01 \\
\hline Age & .12 & .23 & .24 & .01 \\
\hline Annual household income & -.26 & .008 & .004 & .96 \\
\hline Partner's physical violence & .41 & $<.001$ & .06 & .54 \\
\hline Current level of depression & .54 & $<.001$ & .36 & $<.001$ \\
\hline
\end{tabular}


Table 3

Hierarchical Regression Analysis for Variables Predicting Somatization Scores for Women and

$\underline{\text { Men }}(\underline{\mathrm{N}}=101$ women, 101 men $)$

Women Men

$\begin{array}{lllllllll}\text { Variable } & B & S E B & \beta & \Delta R^{2} & B & S E B & \beta & \Delta R^{2}\end{array}$

Step 1

Somatization Score

\begin{tabular}{|c|c|c|c|c|c|c|c|c|}
\hline Age & .004 & .006 & .07 & & .02 & .005 & $.29 * *$ & \\
\hline Household income & -.06 & .03 & $-.17^{\dagger}$ & & .01 & .03 & .04 & \\
\hline $\begin{array}{l}\text { Partner's physical violence } \\
\text { ep } 2\end{array}$ & .37 & .10 & $.35 * * *$ & $.18^{* * *}$ & .07 & .09 & .08 & $.09 *$ \\
\hline Age & .001 & .006 & .02 & & .01 & .005 & $.27 * *$ & \\
\hline Household income & -.05 & .03 & -.14 & & .01 & .03 & .04 & \\
\hline Partner's physical violence & .36 & .10 & $.37 *$ & & .04 & .09 & .04 & \\
\hline $\begin{array}{l}\text { Childhood trauma } \\
\text { ep } 3\end{array}$ & .005 & .002 & $.22 * *$ & $.05^{*}$ & .01 & .003 & $.34 * * *$ & $.12^{* * * *}$ \\
\hline Age & .002 & .01 & .03 & & .02 & .005 & $.30 * *$ & \\
\hline Household income & -.02 & .03 & -.07 & & .01 & .03 & .03 & \\
\hline Partner's physical violence & .34 & .10 & $.32 * *$ & & .06 & .08 & .06 & \\
\hline Childhood trauma & .002 & .002 & .07 & & .01 & .003 & $.27 * *$ & \\
\hline Fearful attachment & .18 & .08 & $.33^{*}$ & & .10 & .06 & .18 & \\
\hline Dismissing attachment & -.03 & .08 & -.04 & & .07 & .07 & .12 & \\
\hline Preoccupied attachment & .05 & .08 & .07 & & -.08 & .06 & -.13 & \\
\hline $\begin{array}{l}\text { Secure attachment } \\
\text { ep } 4\end{array}$ & .05 & .10 & .06 & $.07^{\dagger}$ & -.05 & .07 & -.08 & $.11 * *$ \\
\hline Age & .003 & .006 & .05 & & .02 & .005 & $.30 * *$ & \\
\hline Household income & -.005 & .03 & -.02 & & .01 & .03 & .04 & \\
\hline Partner's physical violence & .30 & .10 & $.28 * *$ & & .06 & .08 & .06 & \\
\hline Childhood trauma & .0004 & .002 & .02 & & .01 & .003 & $.24 * *$ & \\
\hline Fearful attachment & .14 & .07 & $.25^{\dagger}$ & & .07 & .06 & .14 & \\
\hline Dismissing attachment & -.02 & .07 & -.02 & & .07 & .07 & .12 & \\
\hline Preoccupied attachment & .02 & .08 & .03 & & -.08 & .06 & -.13 & \\
\hline Secure attachment & .08 & .09 & .10 & & -.05 & .07 & -.07 & \\
\hline Current depression & .02 & .005 & $.36 * *$ & $.09 * *$ & .01 & .007 & .13 & .01 \\
\hline
\end{tabular}

